\title{
Ballroom Dance as a Form of Rehabilitation: A Systematic Review
}

\author{
Meredith Wells and Feng Yang *(D) \\ Department of Kinesiology and Health, Georgia State University, Atlanta, GA 30303, USA; \\ mwells19@student.gsu.edu \\ * Correspondence: fyang@gsu.edu; Tel.: +1-404-413-8357
}

\footnotetext{
check for updates

Citation: Wells, M.; Yang, F.

Ballroom Dance as a Form of

Rehabilitation: A Systematic Review.

Biomechanics 2021, 1, 307-320.

https://

doi.org/10.3390/biomechanics1030026
}

Academic Editors: Redha Taiar Yuri Ivanenko and João R. Vaz

Received: 10 September 2021

Accepted: 15 October 2021

Published: 20 October 2021

Publisher's Note: MDPI stays neutral with regard to jurisdictional claims in published maps and institutional affiliations.

Copyright: (c) 2021 by the authors. Licensee MDPI, Basel, Switzerland. This article is an open access article distributed under the terms and conditions of the Creative Commons Attribution (CC BY) license (https:// creativecommons.org/licenses/by/ $4.0 /)$.

\begin{abstract}
Chronic health problems, such as neurological conditions or long-lasting diseases, impair patients' physical and mental functions with a subsequent reduction in overall quality of life. The purpose of this systematic review was to summarize how ballroom dance is being investigated as a rehabilitative method in individuals with neurological or medical diseases. A systematic literature search was conducted in databases including MEDLINE, SPORTDiscus, and PubMed. Of 728 articles located and titles and abstracts screened, 12 studies were included in this review. Study groups included Parkinson's disease (4 studies), multiple sclerosis (2), spinal cord injury (1), stroke (1), dementia (1), cancer (2), and diabetes (1). Ballroom dances utilized included a combination of smooth and rhythm dances. Results revealed that ballroom dance is effective in improving gait functions, balance, and quality of life among various populations living with chronic neurological or medical conditions. In addition, ballroom dance is safe and associated with a low attrition rate $(7.7 \%)$. There is increasing evidence to support ballroom dance as a feasible and effective intervention for adults with chronic neurological disorders or medical diseases. Further large-scale, randomized controlled trials are needed to examine the mechanisms, effectiveness, retention, and safety of ballroom dance as a rehabilitative intervention.
\end{abstract}

Keywords: ballroom; dance; chronic disease; movement disorder; movement therapy

\section{Introduction}

Neurological disorders are diseases of the nervous system which encompass the brain, spinal cord, and nerves. The nervous system plays a critical role in controlling human movements and motor coordination; thus, neurological disorders usually compromise body balance, strength, sensation, cognition, and coordination [1]. Such impairments can result in limited mobility and an increased risk of falling [2,3]. The restricted mobility and increased risk of falling, regardless of whether a physical injury occurs, can lead to a fear of falling, decreased independence, reduced employability, less social participation and poor quality of life [4,5]. The common chronic neurological diseases include Parkinson's disease (PD), multiple sclerosis (MS), stroke, spinal cord injury, and dementia [6].

Some chronic medical conditions, such as cancer and diabetes, can also physically and mentally affect individuals in negative ways $[7,8]$. For example, cancer patients are at an increased risk for progressive disease as well as developing additional conditions such as cardiovascular disease [8]. Most adults with metabolic disorders, such as diabetes or obesity, tend to have a sedentary lifestyle. Increasing physical activity can be challenging due to an aversion to and poor tolerance for exercise [7]. Therefore, it is imperative to develop effective programs to improve physical and mental functions for individuals with chronic neurological diseases or medical conditions.

It has been acknowledged that physical exercises can provide health benefits to populations with various chronic medical conditions $[9,10]$. For example, exercise can decrease the health risk of other diseases, counteract symptoms common in MS, and thereby increase 
the quality of life [11,12]. Similarly, physical activity decreases compounding health risks and can improve physical functioning, fatigue, social well-being, and quality of life in cancer patients [8]. Additionally, physical activity has been shown to be beneficial for individuals with mild cognitive impairment [13]. However, the benefits of physical activity only continue as long as the activity continues. In populations where physical activity is challenging, such as those with chronic health problems, dance is an option that has been reported to be enjoyable and, thus, sustainable over extended periods of time [14]. Ballroom dance, specifically, has been shown to lead to improved balance and quality of life in various special populations $[8,15,16]$.

An improved cardiorespiratory function is essential for health and physical fitness. Participating in regular recreational ballroom dance has been demonstrated to positively impact the cardiovascular system by enhancing resting heart rates and improving cardiac responses to exercise [17], and serving as a moderate to vigorous form of activity [17-21]. Considering the physiological benefits and social characteristics, ballroom dance may be attractive for cardiovascular and general health improvements in individuals that struggle to adhere to traditional exercise programs [17].

A recent study found that participants felt that partnered dance improves their physical fitness, physical coordination, memory, and focus [14]. Multiple studies reported that partnered dance increased self-confidence in participants [14,22]. Additionally, ballroom dance has been associated with improvements in cognitive functioning [23]. Simple motor skills, such as running, are predictable and involve less goal-directed movement. However, complex motor skills, such as ballroom dance steps, incorporate high levels of coordinated body movements that require practice, which may have a greater impact on cognitive processes [23]. In addition, it was documented that ballroom dance can enhance mood and is enjoyable to participate in [14,22-24]. While typical exercise modalities are less effective in motivating regular exercise, ballroom dance, by its fun, social, and motivating characteristics, could be a form of physical activity with the potential for high compliance among participants $[17,18]$.

Developments in the medical field have been accompanied by a growth in the elderly population, as well as individuals with chronic diseases, who are at an increased risk of falling [5,25]. Ballroom dance movements, such as forward, backward, and sideways stepping, spinning, tip-toeing, heel rising, and turning, could influence the human body biomechanically by improving muscle strength, and therefore, gait and balance, thereby minimizing the risk of falling [25]. Thus, ballroom dance has been used as a tool for improving balance in older adults and populations of individuals with chronic neurological and medical diseases.

Despite its increasing popularity and promising health benefits, no systematic review has discussed the positive outcomes of ballroom dance across studies among people with chronic neurological or medical conditions. This may create a barrier for the research and rehabilitative fields to develop ballroom dance-based interventions for individuals with chronic movement disorders or medical conditions. Therefore, the purpose of this study was to conduct a systematic review of the literature to summarize how ballroom dance is being used and investigated in individuals with chronic neurological or medical diseases and disorders. A meta-analysis was not conducted due to a lack of consistent variables across studies and populations. The diseases or disorders of interest for this review are a combination of chronic neurological or medical diseases, including Parkinson's disease, multiple sclerosis, spinal cord injury, stroke, dementia, cancer, and diabetes. The objectives of this study were three-fold: (1) to describe dance interventions used in chronic disease/disorder populations based on the frequency, intensity, duration, and type; (2) to discuss the feasibility of dance interventions as it relates to participant dropout, adherence, and adverse events; and (3) to investigate the effect of ballroom dance on balance, gait, functional mobility, cognitive ability, and quality of life in chronic disease/disorder populations. This review would provide information supporting the promising effects of 
ballroom dance as an intervention in improving health conditions and quality of life in people living with chronic neurological or medical diseases.

\section{Materials and Methods}

An electronic search of the literature was conducted in January 2020. The following databases were included: MEDLINE with Full Text, SPORTDiscus with Full Text, and PubMed. Search strategies using combinations of subject headings and keywords were developed to identify appropriate studies. Search terms used are listed in Table 1. Updated searches using the same strategy were conducted in August 2020, and again in January 2021. Reference lists from relevant articles were also examined to identify additional studies that may have been missed by the electronic search.

Table 1. Summary of database search terms that were applied to all databases.

\begin{tabular}{cc}
\hline Number & Search Terms \\
\hline 1 & Ballroom dance OR ballroom dancing \\
\hline 2 & Partner dance \\
\hline 3 & Cancer patients OR oncology patients OR patients with cancer AND \\
ballroom dance OR ballroom dancing
\end{tabular}

The titles of all search results were screened to identify potentially relevant studies for further review. Abstracts of articles identified as potentially relevant were assessed to determine if they met the inclusion criteria. Inclusion criteria included studies in English that investigated: (1) an adult population with diseases or disorders listed in Table 1 that affect the quality of life and are not typical of aging; (2) the effects of a ballroom dance intervention that assessed any aspect of physical and mental functions, including but not limited to: gait, balance, functional mobility, depression, or enjoyment. We defined a ballroom dance intervention as any regular intervention program that featured learning ballroom dance patterns. Studies were excluded if they (1) used a dance intervention other than ballroom or (2) investigated a population that did not suffer from a long-lasting disorder or disease. Given the aim of the review, there were no restrictions on publication type or study design.

Articles that met the inclusion criteria were reviewed to extract details related to the outcomes of interest. Publication details such as year of publication study design and study group demographics were retrieved from each study.

\section{Results}

\subsection{Flow of Studies through The Review Process}

A total of 726 articles were initially found through database searching, and two more were identified from the reference lists of articles, making 728 potential articles (Figure 1). After the removal of duplicates (111) and titles or abstracts not pertaining to the research purpose (598), 19 potentially relevant articles were identified. Among them, six were excluded, as five studies did not include a ballroom dance protocol, and one study 
only reported proposed methodology. This led to a total of 13 articles included in the review. Two of the thirteen articles were based on the same participants following the same experimental protocol but reported different outcome measures [15,26]. These two articles were combined and included in our review. Therefore, our review involves 12 studies reported in 13 articles (Figure 1).

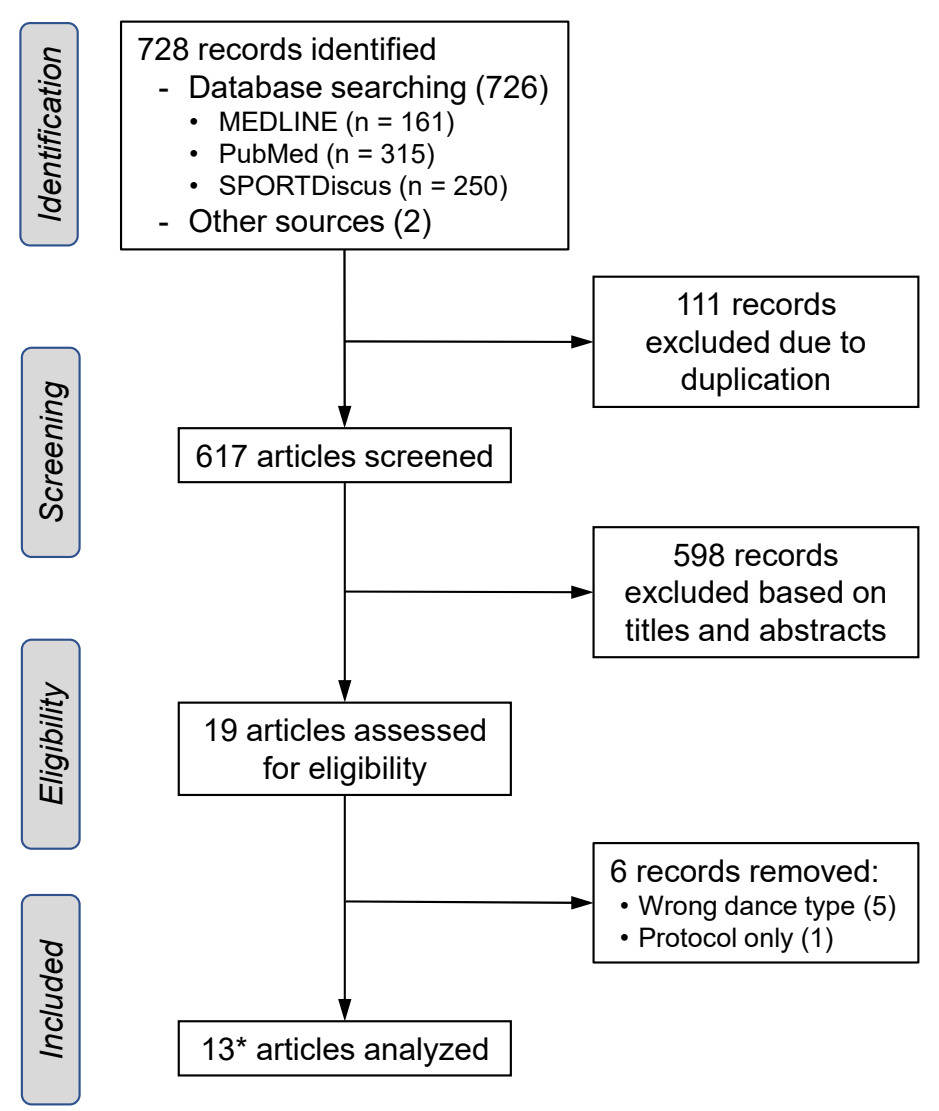

Figure 1. The flow diagram of selecting studies for the present systematic review according to the guidelines of the Preferred Reporting Items for Systematic Reviews and Meta-Analysis. * Two articles $[15,26]$ reported on the same study; thus, the final review includes 13 articles regarding 12 studies.

Among the 12 studies, there were three randomized controlled studies [13,26,27], two pre-post studies with a control group $[8,11]$, two pre-post studies without a control group [12,16], two single group pre-post studies [28,29], one case study [30], one longitudinal study [7], and one study with an unspecified design [31]. The results of 11 studies, including the two from the same data set, were published in academic journals $[7,8,11-13,15,16,26,27,30,31]$, and two were published as abstracts [28,29].

\subsection{Characteristics of the Studies}

The characteristics of the dance interventions, including frequency, duration, intensity, and dance style, were retrieved. Additionally, indicators of feasibility were extracted, such as dropouts, adverse events, and adherence to the dance intervention. Details for each of the included studies are summarized in Tables 2 and 3. Of the 12 trials, four studied PD [16,26-28], two studied MS [11,12], one studied spinal cord injury wheelchair users [29], one studied stroke [30], one studied dementia [13], two studied cancer [8,31], and one studied diabetes [7]. The majority of the studies included a relatively small sample size. The smallest sample size was in a case study with a stroke patient [30], and the largest sample size was 129 individuals with dementia [13]. The average sample size across the populations was 30 , with the larger sample sizes belonging to the PD $(n=51)$, dementia 
( $n=129)$, and diabetes $(n=100)$ studies and the smaller sample sizes belonging to studies concerning people with MS $(n=13)$. The 12 included studies involved 473 participants (194 males and 243 females-one study did not specify gender). The age of the participants ranged between 32 [12] and 79 [16] years old.

All of the studies included a ballroom dance intervention of some kind. Two of the studies with PD utilized Argentine tango [16,28], while the other two utilized a combination of the Foxtrot, Waltz, Tango, Rumba, and Cha Cha. The two studies on MS used Salsa dance [12], and a combination of the Foxtrot, Waltz, and Rumba [11]. The study with spinal cord injury patients applied Salsa, Tango, and Rumba [29]. The case study on stroke utilized Tango [30]. The study with individuals with dementia utilized a combination of ballroom dances, including the Foxtrot, Waltz, Tango, Rumba, Cha Cha, and Swing, among others [13]. One study with cancer patients taught the Foxtrot, Waltz, Cha Cha, and Swing [8], while the second study with cancer patients [31] and the study with individuals with diabetes [7] utilized unspecified ballroom dances.

The majority of the dance classes were an hour long and met twice a week, with three studies utilizing longer dance sessions $(1.5 \mathrm{~h})[7,30,31]$ and one study only meeting once a week [31]. Only four of the studies reported on the intensity of the dance sessions, which was moderate $[7,8,11,12]$. One study reported adverse events in which one participant reported leg pain due to their condition, and a second participant fell in class but did not sustain any injuries [27]. Most of the studies had a high adherence rate, with minimal dropouts. The highest dropout rate was 20 percent $[8,16,26]$, the lowest dropout rate was zero $[11,12,30]$, and two studies did not report the number of participants that dropped out. Over the training course, 24 participants in the ballroom dance groups in the 10 studies, which reported the dropout information, withdrew from the studies before completing the training protocol. This led to an overall attrition rate of $7.7 \%(=24 / 309)$.

Table 2. Summary of the study design, disorder, participants, type, frequency, and intensity of the ballroom dance interventions for the included articles.

\begin{tabular}{|c|c|c|c|c|c|c|}
\hline Study & Study Design & Disease/Disorder & $\begin{array}{l}\text { Participants (n; Age } \\
\text { (SD)) }\end{array}$ & Type of Dance & $\begin{array}{l}\text { Frequency of } \\
\text { Intervention }\end{array}$ & Intensity \\
\hline $\begin{array}{c}\text { Blandy et al, } 2015 \\
{[28]}\end{array}$ & $\begin{array}{l}\text { Single-group } \\
\text { pre-post test }\end{array}$ & PD & $\begin{array}{c}6 \text { people with PD } \\
\text { (3 male), age: } 64(6.28)\end{array}$ & Argentine Tango & $\begin{array}{c}1 \mathrm{~h} \text {, twice per } \\
\text { week, for } 4 \text { weeks }\end{array}$ & Not reported \\
\hline $\begin{array}{c}\text { Hackney \& } \\
\text { Earhart, } 2010 \text { [16] }\end{array}$ & $\begin{array}{c}\text { Randomized, } \\
\text { pre-post } \\
\text { without control }\end{array}$ & PD & $\begin{array}{c}39 \text { people with PD-15 } \\
\text { partner }(13 \text { male), age: } \\
69.6(8.5) ; 16 \\
\text { non-partner }(15 \text { male }) \text {, } \\
\text { age: } 69.6(9.5)\end{array}$ & $\begin{array}{l}\text { Partnered and } \\
\text { non-partnered } \\
\text { Argentine tango }\end{array}$ & $\begin{array}{l}1 \mathrm{~h} \text {, twice per } \\
\text { week, for } \\
10 \text { weeks }\end{array}$ & Not reported \\
\hline $\begin{array}{l}\text { Hackney et al, } \\
2012 \text { [30] }\end{array}$ & Case Study & Stroke & 73-year-old male & Tango & $\begin{array}{c}20 \text { sets of } 1.5-h \\
\text { dance class over } \\
12 \text { weeks }\end{array}$ & Not reported \\
\hline $\begin{array}{l}\text { Hulbert et al, } 2017 \\
\text { [27] }\end{array}$ & $\begin{array}{l}\text { Randomized } \\
\text { controlled }\end{array}$ & PD & $\begin{array}{l}27 \text { people with PD: } \\
\text { intervention } \\
(15)-7 \text { male, age: } 73.4 \\
\text { (4.9); control (12)—5 } \\
\text { male, age: } 71.7(5.1)\end{array}$ & $\begin{array}{l}\text { Fox trot, Waltz, } \\
\text { Tango, Rumba, } \\
\text { Cha Cha, } \\
\text { Rock-n-roll, } \\
\text { Social dance }\end{array}$ & $\begin{array}{c}1 \text { hour, twice per } \\
\text { week, for } \\
10 \text { weeks }\end{array}$ & Not reported \\
\hline $\begin{array}{c}\text { Kunkel et al, } 2017 \\
{[15,26]^{*}}\end{array}$ & $\begin{array}{l}\text { Randomized } \\
\text { controlled trial }\end{array}$ & PD & $\begin{array}{l}51 \text { people with PD: } \\
\text { intervention (36)-19 } \\
\text { male, age: } 71(7.7) ; \\
\text { control (15)—6 male, } \\
\text { age: } 69.7(6)\end{array}$ & $\begin{array}{l}\text { Fox trot, Waltz, } \\
\text { Tango, Cha Cha, } \\
\text { Rock-n-roll, and } \\
\text { Rumba }\end{array}$ & $\begin{array}{l}1 \mathrm{~h} \text {, twice a week, } \\
\text { for } 10 \text { weeks }\end{array}$ & Not reported \\
\hline $\begin{array}{l}\text { Lazarou et al, } \\
2017 \text { [13] }\end{array}$ & $\begin{array}{l}\text { Single-blinded } \\
\text { randomized } \\
\text { controlled, } \\
\text { pre-post trial }\end{array}$ & Dementia & $\begin{array}{c}\text { Intervention Group-66 } \\
\text { (13 male), age: } 65.9 \\
\text { (10.8); Control } \\
\text { Group-63 (15 male), } \\
\text { age: } 67.9(9.5)\end{array}$ & $\begin{array}{c}\text { Tango, Waltz, } \\
\text { Viennese Waltz, } \\
\text { Fox Trot, Rumba, } \\
\text { Cha Cha, Swing, } \\
\text { Salsa, Merengue, } \\
\text { Hustle }\end{array}$ & $\begin{array}{c}60 \text { min, twice per } \\
\text { week for } \\
40 \text { weeks }\end{array}$ & Not reported \\
\hline $\begin{array}{l}\text { Mandelbaum } \\
\text { et al, } 2016 \text { [12] }\end{array}$ & $\begin{array}{l}\text { Pre-post study } \\
\text { with no control }\end{array}$ & MS & $\begin{array}{c}8 \text { people with MS } \\
\text { ( } 3 \text { male), aged } 32 \text { to } 63\end{array}$ & Salsa & $\begin{array}{l}60 \mathrm{~min} \text {, twice per } \\
\text { week for } 4 \text { weeks }\end{array}$ & Moderate \\
\hline
\end{tabular}


Table 2. Cont.

\begin{tabular}{|c|c|c|c|c|c|c|}
\hline Study & Study Design & Disease/Disorder & $\begin{array}{l}\text { Participants (n; Age } \\
\text { (SD)) }\end{array}$ & Type of Dance & $\begin{array}{l}\text { Frequency of } \\
\text { Intervention }\end{array}$ & Intensity \\
\hline $\begin{array}{l}\text { Mangeri et al, } \\
\text { 2014 [7] }\end{array}$ & Longitudinal & Diabetes & $\begin{array}{c}100 \text { people- }-47 \text { with } \\
\text { type } 2 \text { diabetes, } 53 \\
\text { with obesity ( } 52 \text { male), } \\
\text { age: } 59\end{array}$ & $\begin{array}{l}\text { Latin and } \\
\text { Standard } \\
\text { Ballroom }\end{array}$ & $\begin{array}{c}2 \text { hours, twice per } \\
\text { week for } \\
6 \text { months }\end{array}$ & $\begin{array}{c}\text { 4-7 METs } \\
\text { (depending on } \\
\text { dance type) }\end{array}$ \\
\hline $\begin{array}{c}\text { Masters et al, } \\
2013 \text { [29] }\end{array}$ & $\begin{array}{l}\text { Uncontrolled } \\
\text { pilot study }\end{array}$ & Spinal Cord & $\begin{array}{c}7 \text { paraplegia and } 8 \\
\text { tetraplegia } \\
\text { individuals }\end{array}$ & $\begin{array}{l}\text { Salsa, Tango, } \\
\text { Rumba }\end{array}$ & $\begin{array}{l}4 \text { hours a week } \\
\text { for } 6 \text { weeks }\end{array}$ & Not reported \\
\hline $\begin{array}{c}\text { Ng et al, } 2019 \\
\text { [11] }\end{array}$ & $\begin{array}{l}\text { Pre-post study } \\
\text { with control }\end{array}$ & MS & $\begin{array}{l}13 \text { people with MS-7 } \\
\text { intervention, age: } 49 ; \\
6 \text { control, age: } 55\end{array}$ & $\begin{array}{l}\text { Rumba, Fox trot, } \\
\text { Waltz, and } \\
\text { Push-pull }\end{array}$ & $\begin{array}{c}1 \mathrm{~h} \text {, twice per } \\
\text { week for } 8 \text { weeks }\end{array}$ & Not reported \\
\hline $\begin{array}{c}\text { Pisu et al, } 2017 \\
{[8]}\end{array}$ & $\begin{array}{l}\text { Pre-post study } \\
\text { with control }\end{array}$ & Cancer & $\begin{array}{l}31 \text { couples: cancer } \\
\text { survivors-age: } 57.9 \\
(9.3) ; \text { partners-age: } \\
60.7(9.9)\end{array}$ & $\begin{array}{c}\text { Foxrot, Waltz, } \\
\text { Cha Cha, and } \\
\text { East Coast Swing }\end{array}$ & $\begin{array}{l}45 \text { min, } 10 \text { private } \\
\text { and } 2 \text { group } \\
\text { lessons over } \\
12 \text { weeks }\end{array}$ & $5 \mathrm{METs} / \mathrm{hr}$ \\
\hline $\begin{array}{l}\text { Schmidt et al, } \\
2018 \text { [31] }\end{array}$ & Unspecified & Cancer & $\begin{array}{c}11 \text { couples-Age: } 6 \\
\text { were } 56-65 \text { years, } 6 \\
\text { were } 66-75 \text { years, and } \\
1 \text { was over } 75\end{array}$ & $\begin{array}{l}\text { Ballroom- } \\
\text { unspecified }\end{array}$ & $\begin{array}{l}90 \text { min, offered } \\
\text { once a week for } \\
8 \text { months }\end{array}$ & Varied \\
\hline
\end{tabular}

Note: PD = Parkinson's disease; MS = Multiple sclerosis; MET = Metabolic equivalent. *: Two articles reported on the same study and their results are reported together $[15,26]$.

Table 3. Summary of dropouts, adverse events, outcome measures, and results of the ballroom dance interventions for the included studies.

\begin{tabular}{cccc}
\hline Study & Dropouts & Adverse Events & Outcome Measures \\
\hline $\begin{array}{c}\text { Blandy et al., } 2015 \\
\text { [28] }\end{array}$ & $\begin{array}{c}89 \% \text { adherence, and } 1 \\
\text { dropout }\end{array}$ & None & $\begin{array}{c}\text { Safety, adherence, overall } \\
\text { health, and depression } \\
\text { scores }\end{array}$ \\
\end{tabular}

Hackney \& Earhart, $\quad 20 \%$ withdrew (4 $2010[16] \quad$ from each condition)
None reported

Hackney et al., 2012 [30] NA

None reported

1 adverse event (leg pain) was linked to

Hulbert et al., 2017 [27]
3 dance participants dropped out the participant's

condition, and 1

participant fell in

class with no injury
BBS, tandem stance, one-leg stance, TUG, 6MWT, comfortable and

fast walking examined gait

velocity, cadence, stride length, swing $\%$, and double support \%, program experience

30 s chair stand, walking speed and variability, step length variability, and single support time during habitual, backward, and

Findings

Health and depression scores improved, and intervention was deemed safe with high adherence

Improved BBS, comfortable and fast walking velocity, one-leg and tandem stance time, cadence, double support $\%$, fast walking swing $\%$, stride length, $6 \mathrm{MWT}$, and reported physical well-being

Improved chair stand, BBS, FRT, TUGc, TUG, and 6MWT, decreased balance confidence, unchanged mental health and visual QOL, reported feeling improved walking, coordination, strength, endurance, and mood. mental and visual OOL and depression using self-report questionnaires
Controls had longer latencies between segments, and increased rotation. Dancers showed shorter latency between segments, decreased rotation throughout the body segments, and increased weight transfer 
Table 3. Cont

\begin{tabular}{|c|c|c|c|c|}
\hline Study & Dropouts & Adverse Events & Outcome Measures & Findings \\
\hline $\begin{array}{c}\text { Kunkel et al., } 2017 \\
{[15,26]}\end{array}$ & $\begin{array}{c}5 \text { dance participants } \\
\text { dropped out }\end{array}$ & None reported & $\begin{array}{c}\text { BBS, Spinal Posture, SS180, } \\
\text { TUG, PDQ39, ABC, } \\
\text { Phone-FITT, Euroqual-5D, } \\
\text { 6MWT }\end{array}$ & $\begin{array}{l}\text { Improved 6MWT, TUG, } \\
\text { and SS180. Study } \\
\text { demonstrated feasibility }\end{array}$ \\
\hline $\begin{array}{c}\text { Lazarou et al., } 2017 \\
\text { [13] }\end{array}$ & $\begin{array}{l}3 \text { (due to family } \\
\text { problems) }\end{array}$ & None reported & $\begin{array}{l}\text { Neuropsychological } \\
\text { battery of tests to evaluate } \\
\text { attention, working } \\
\text { memory, memory, } \\
\text { executive functioning, and } \\
\text { language-MMSE, RBMT, } \\
\text { FAS, NPI, GDS, BDI, } \\
\text { Hamilton Scale for } \\
\text { Depression, PSS, Beck } \\
\text { Anxiety Inventory, FRSSD, } \\
\text { FUCAS, TRAIL-B, ROCFT, } \\
\text { RAVLT, and TEA }\end{array}$ & $\begin{array}{l}\text { Improved MMSE, MOCA, } \\
\text { TEA, NPI, RAVLT, FAS, } \\
\text { RBMT1, RBMT2, ROCFT, } \\
\text { and GDS in the dance } \\
\text { group. No improvements } \\
\text { in the control group. }\end{array}$ \\
\hline $\begin{array}{l}\text { Mandelbaum et al., } \\
2016 \text { [12] }\end{array}$ & $\begin{array}{c}1 \text { participant } \\
\text { completed } 7 \text { of } 8 \\
\text { dance sessions due to } \\
\text { scheduling }\end{array}$ & None & $\begin{array}{l}\text { T25FW, MSWS-12, TUG, } \\
\text { DGI, BBS, MSSS, ABC, } \\
\text { MPAM-R, PDDS, GLTEQ, } \\
\text { MS symptom checklist }\end{array}$ & $\begin{array}{l}\text { Improved TUG, MSWS-12, } \\
\text { DGI, MS symptom } \\
\text { checklist, and time spent } \\
\text { exercising }\end{array}$ \\
\hline $\begin{array}{c}\text { Mangeri et al., } 2014 \\
\text { [7] }\end{array}$ & $\begin{array}{l}2 \% \text { dropped out, } 77 \% \\
\text { attended over } 70 \% \text { of } \\
\text { the planned sessions }\end{array}$ & None reported & $\begin{array}{l}\text { MET-hours/week, } \\
\text { anthropometric data, } \\
\text { weight, waist } \\
\text { circumference, 6MWT, } \\
\text { EMME-3 }\end{array}$ & $\begin{array}{l}\text { Both groups decreased } \\
\text { body weight, waist } \\
\text { circumference, fasting } \\
\text { glucose, and liver enzymes. } \\
\text { Both groups improved } \\
\text { 6MWT and } \\
\text { MET-hours/wk. }\end{array}$ \\
\hline $\begin{array}{c}\text { Masters et al., } 2013 \\
\text { [29] }\end{array}$ & Not reported & None reported & $\begin{array}{l}\text { Weight, subjective pain at } \\
\text { rest, isometric strength, } \\
\text { upper body ROM, reaction } \\
\text { time, wheelchair agility, } \\
\text { 6-min distance, and } \\
\text { coordination }\end{array}$ & $\begin{array}{l}\text { Improved upper extremity } \\
\text { and trunk ROM, upper } \\
\text { body strength, 6-min } \\
\text { distance, coordination, and } \\
\text { decreased weight, resting } \\
\text { pain, and reaction time }\end{array}$ \\
\hline Ng et al., 2019 [11] & 0 & None reported & $\begin{array}{l}\text { PROMIS-GH, FIS, BDI, } \\
\text { MSSS, T25FW, 9-HPT, } \\
\text { PASAT, BBS, DGI }\end{array}$ & $\begin{array}{l}\text { Improved PROMIS-GH, } \\
\text { FIS, BDI, BBS, MS } \\
\text { Functional Composite } \\
\text { Score, and PASAT in the } \\
\text { dance group. Control } \\
\text { group showed no changes. }\end{array}$ \\
\hline Pisu et al., 2017 [8] & $20 \%$ & None reported & $\begin{array}{c}\text { GLTEQ, 6MWT, SF-36, } \\
\text { Dyadic Trust Scale, DAS-7, } \\
\text { perceived self-disclosure } \\
\text { questionnaire }\end{array}$ & $\begin{array}{l}\text { Intervention group showed } \\
\text { improved physical activity, } \\
\text { functional capacity, QOL, } \\
\text { vitality, social functioning, } \\
\text { and mental health and } \\
\text { dyadic trust. Control group } \\
\text { improved body pain and } \\
\text { functional capacity }\end{array}$ \\
\hline
\end{tabular}


Table 3. Cont.

\begin{tabular}{|c|c|c|c|c|}
\hline Study & Dropouts & Adverse Events & Outcome Measures & Findings \\
\hline $\begin{array}{c}\text { Schmidt et al., } 2018 \\
\text { [31] }\end{array}$ & Not reported & None & Daily reports of well-being & $\begin{array}{l}\text { Well-being increased } \\
\text { during class and returned } \\
\text { to starting level during the } \\
\text { next } 6 \text { days }\end{array}$ \\
\hline
\end{tabular}

Note: BBS = Berg Balance Scale; TUG = Timed-Up-and-Go; 6MWT = 6-min walk test; TUGc = Timed-Up-and-Go cognitive; QOL = Quality of Life; GLTEQ = Godin Leisure-Time Exercise Questionnaire; SF-36 = Short Form Health Survey; DAS-7 = Dyadic Adjustment Scale; MMSE = Mini Mental State Examination; RBMT = Rivermead Behavioral Memory Test; FAS = Verval Fluency F-A-S test; NPI = Neuropsychiatric Inventory; GDS = Global Deterioration Scale; BDI = Beck Depression Inventory; PSS = Perceived Stress Scale; FRSSD = Functional Rating Scale for Dementia; FUCAS = Functional and Cognitive Assessment Test; TRAIL-B = Trail Making Test part-B; ROCFT-copy and delayed recall = Rey Osterrieth Complex Figure Test copy and delay recall; RAVLT = Rey Auditory Verbal Learning Test; TEA = Test of Everyday Attention; MOCA = Montreal Cognitive Assessment Test; FRT = Functional Reach Test; ROM = Range of Motion; T25FWT = Timed 25-foot Walk Test; PDQ39 = Parkinson Disease Questionnaire 39; ABC = Activities-specific Balance Confidence scale; Phone-FITT = questionnaire recording recreational activities; Euroquol = quality of life measure; PROMIS-GH = Patient-Reported Outcomes Measurement Information System-Global Health; FIS = Fatigue Impact Scale; MSSS = Multiple Sclerosis Self-Efficacy Scale; 9-HPT = 9-Hole Peg Test; PASAT = 3-s Paced Auditory Serial Addition Test; DGI = Dynamic Gait Index; MSWS-12 = MS Walking Scale-12; MPAM-R = Motives for Physical Activity Measure-Revised; PDDS = Patient Determined Disease Steps; SS180 = Standing Start 180 Turn Test; EMME-3 = questionnaire for healthy diet and habitual physical activity.

\subsection{Study Specifics}

\subsubsection{Parkinson's Disease}

Parkinson's disease is a common, progressive neurological condition that can lead to a deterioration of spinal posture, mobility, and stability, thereby leading to falls [15]. A 2010 study compared the effects of partnered and non-partnered dance on balance and mobility in 39 individuals with PD [16]. Participants learned either partnered or nonpartnered Tango during two one-hour classes each week for 10 weeks. Participants in both groups were taught by the same instructor, danced to the same music, and followed the same class sequence. Participants with PD always danced with individuals without PD. Following the intervention, participants in both groups showed improvements in balance, comfortable and fast walking velocity, and walking cadence immediately following and one-month post-intervention. Though both groups improved equally, the participants in the partnered dance group reported feeling more enjoyment and a greater interest in continuing the classes.

A later study aimed to determine the feasibility of implementing an Argentine Tango intervention for individuals with PD [28]. Participants attended a one-hour Argentine Tango dance class twice a week for four weeks. Researchers found the intervention to be safe, with high adherence. Additionally, both health and depression scores improved. These results indicate that Argentine tango is a feasible and safe dance program for individuals with mild to moderate PD [28].

Another study determined the potential for using ballroom dance as an intervention for patients with PD based on feasibility and enjoyment. The first phase consisted of a randomized controlled trial that sought to determine the feasibility of a partnered ballroom dance protocol with PD patients [26]. The dance group, consisting of 31 individuals with PD, participated in two one-hour dance classes weekly for 10 weeks and learned the Foxtrot, Waltz, Tango, Rumba, Cha Cha, and Rock-n-Roll. The dance group always danced with age-matched healthy individuals. The control group, which consisted of 15 individuals with PD, was instructed to continue with their usual routine. The primary assessments were balance and spinal posture, along with a few additional tests, including the Timed-Up-and-Go test and the 6-min walk test. Results showed minimal differences in balance, possibly due to the small sample size. However, the dance group did make small improvements in the six-minute walk test. Participants in the dance group also reported finding the dance classes to be enjoyable. Therefore, the authors concluded that using ballroom dance as an intervention for individuals with PD is feasible.

The second part of the previous study was to determine the experiences of individuals with PD and their dance partners through interviews in order to identify factors that may affect the enjoyment of partnered ballroom dance classes [15]. Of the participants in the 
original experimental group, seven men and seven women, along with their partners, were recruited to partake in a qualitative study. The partners were a mix of spouses, friends, and volunteer partners. The results indicated that those who were partnered with a spouse gained the greatest enjoyment from the experience. Those partnered with experienced dancers, or if they were able to build a good rapport with their partners, also reported feeling a sense of achievement and enjoyment from the dance classes. It was found that the experience participants had in the dance classes was greatly influenced by the relationship and compatibility participants felt with their partners.

Another study analyzed the effects of ballroom dance on whole-body coordination when turning around in people with PD [27]. The dance group, composed of 15 individuals with PD, participated in two one-hour dance classes each week for 10 weeks and learned the Foxtrot, Waltz, Tango, Rumba, Cha Cha, and Rock-n-Roll, while the control group, which included 12 individuals with PD, were instructed to continue their usual care. Wholebody coordination during turning was assessed using 12 on-the-spot turns before and after the intervention. The 12 turns were split up with three predicted turns each to the preferred and non-preferred side and three unpredicted turns each to the preferred and non-preferred side, all at a self-selected pace. Results indicated that those who participated in the dance group were better able to coordinate their axial and perpendicular segments and were better at turning their whole body together than the control group. These results demonstrate that partnered ballroom dance may be a beneficial form of rehabilitation and physical activity for individuals with PD [27].

\subsubsection{Multiple Sclerosis}

Multiple sclerosis is a life-altering neurological disease of the central nervous system that may lead to fatigue, depression, and motor impairments [11]. Two pilot studies aimed to determine the plausibility of using ballroom dance as an intervention for people with MS [11,12]. The first pilot study analyzed the effects of Salsa dance on physical activity, gait, balance, and self-efficacy [12]. Participants included eight participants with MS who completed two one-hour Salsa dance classes each week for four weeks. Participants were assessed at baseline, immediately following the intervention, and at 3- and 6-month follow-ups on gait, balance, self-efficacy, motivation, physical activity, and MS symptoms. Results showed increased engagement in physical activity during the intervention period and improvements in gait and balance immediately after and at the 3-month followup compared to baseline. Moreover, the protocol was well tolerated, and participants completed the dance classes with no reported difficulty. These results illustrate that the Salsa dance protocol was well-tolerated, safe, and successful at promoting physical activity in independent individuals with MS. This indicates that Salsa dance may be a promising physical activity for individuals with MS.

The second pilot study evaluated the exercise intensity and feasibility of a ballroom dance protocol, as well as the physical and psychological function in 13 people with MS [11]. The seven participants in the dance group completed two one-hour dance sessions each week for at least six of the eight weeks offered. Dances taught included the Rumba, Foxtrot, Waltz, and Push-Pull. All participants with MS danced with individuals without MS. After the steps were taught, participants were encouraged to use whatever steps they wanted, which provided participants the opportunity to initiate steps in all directions, learn and recall motor patterns, and process multiple sensory stimuli. Following the intervention, the dance group showed an improved health-related quality of life, a trend toward improved fatigue and depression, improved cognition, and a trend toward enhanced balance measures, but no changes in self-efficacy, while the control group illustrated no changes. Participants reported enjoying the dance classes, moving with the music, and interacting with the instructor and other participants, which likely contributed to the enjoyment and improved quality of life. These results suggest that recreational ballroom dance could be adopted as an exercise program to meet activity guidelines for individuals with MS. 


\subsubsection{Spinal Cord Injury}

One study examined the physical benefits of a mixed ability social ballroom dance class for spinal cord injury paraplegic and tetraplegic wheelchair users [29]. Participants attended four hours of social dance classes each week for six weeks where they learned the Salsa, Tango, and Rumba dances. Following the dance protocol, there were significant increases in upper extremity and trunk range of motion, upper body strength, and improved coordination, along with decreases in weight, pain, and reaction time. These improvements show that ballroom dance may be a fun, safe, and social form of exercise with numerous benefits for spinal cord injury wheelchair users.

\subsubsection{Stroke}

Individuals at the chronic stage of stroke engage in less activity and have belowaverage cardiovascular fitness. Additionally, balance and mobility are impaired, making it difficult for them to partake in daily activities and negatively impacting their quality of life [30].

A case study was done to describe the effect of an adapted Tango program on movement functions involving balance, mobility, gait, endurance, dual-task ability, and quality of life in a 73-year-old male with hemiplegia and visual impairment 13 years post-stroke [30]. The participant participated in twenty 1.5-h adapted Tango lessons over the course of 12 weeks. Following the intervention, the participant improved in the chair stand, the Berg Balance Scale, timed up-and-go, and the six-minute walk test. Self-reported physical and mental health and visual quality of life changed little, while balance confidence decreased. However, the participant indicated that he enjoyed the classes, would continue if given the opportunity and was more physically active. He also felt that he improved in walking, coordination, strength, endurance, and mood. This case study provides promising results and illustrates that ballroom dance may provide some health benefits to individuals with chronic stroke.

\subsubsection{Dementia}

A trial with patients experiencing mild cognitive impairment evaluated the impact of ballroom dance class instruction on cognition and mood [13]. Lessons were $60 \mathrm{~min}$ in duration, and were held twice weekly for 40 weeks. The 66 participants in the dance group learned the Tango, Waltz, Viennese Waltz, Foxtrot, Rumba, Cha Cha, Swing, Salsa, Merengue, Hustle, and traditional Greek dance, and dance steps presented became gradually more complex over time. Cognitive assessments were performed by a collection of neuropsychological tests designed to examine attention, working memory, memory, executive functioning, and language before and after the intervention. The dance group showed improvements in almost all parameters following the 10-month period, while the control group showed a decline in performance. These results elicit that dance may be an ideal option for preventing age-related degradations, particularly in people with limited social opportunities and declining cognitive performance.

\subsubsection{Cancer}

A pilot study utilizing a ballroom dance program was performed to determine the potential improvement in quality of life in cancer survivors and their partners [8]. The intervention included 10 private 45-min lessons and two group lessons over the course of 12 weeks, where couples learned the Foxtrot, Waltz, Cha Cha, and East Coast Swing. Following the intervention, the dance group exhibited significant improvements in physical activity, functional capacity, the mental component of quality of life, vitality, social function, and mental health. There were no significant improvements in the partners of the cancer survivors in either group, except for an increase in dyadic agreement and happiness in the ballroom dance partners. At the end of the dance program, cancer survivors reported appreciating the opportunity to ease into physical activity, and both survivors and their partners enjoyed spending time together, working toward a common goal, and laughing 
together. This shows that ballroom dance may have the potential to provide light physical activity and to improve the quality of life in cancer survivors and their partners [8].

A later pilot study assessed the feasibility of ballroom dance for cancer patients and their partners and developed a simple method to evaluate its effects on well-being [31]. The 90-min dance classes were offered once a week for eight months. The intensity of the classes was adapted to the individuals. An anonymous one-question questionnaire allowed participants to rate their well-being on a scale of 1-10. Participants completed this questionnaire immediately before, during, immediately after, and on the return home from the lesson, as well as every evening leading up to the next class. Findings showed that for most of the patients, well-being remained stable or increased during class and then returned to baseline over the following six days. Patients with a low well-being rating in the three days before class experienced notable improvements during class. All but one healthy partner reported well-being as increasing during the class. These findings support the feasibility of ballroom dance classes as a new and alternative modality of physical activity for cancer patients and their partners [8].

\subsubsection{Diabetes}

A longitudinal trial sought to determine the metabolic and clinical effects of dance in individuals with Type 2 diabetes and/or obesity [7]. Participants were enrolled in either a dance program or a self-selected physical activity program based on their personal preferences. The dance program consisted of two-hour dance lessons two times each week for six months. Participants were welcome to dance with their own partners or with other individuals in the class. Both programs detected significantly lower body weight and waist circumference at three months and maintained results at six months. This study highlights the benefits of a dance program as an effective form of physical activity for improving metabolic control and successfully motivating individuals with Type 2 diabetes/obesity to exercise.

\section{Discussion}

The purpose of this review was to summarize how ballroom dance is being used and investigated as an alternative rehabilitation modality for individuals with different chronic neurological or medical disorders. Based on the findings from the 12 included studies, various ballroom dance protocols have been increasingly utilized as interventions for individuals living with chronic neurological conditions or diseases, and numerous health benefits were observed among those populations.

The ballroom dance protocols used in the studies incorporated in this review appeared to result in improvements in gait, balance, and turning around in people with PD [16,26,27]; gait functions, balance, physical activity engagement, quality of life, and cognition in persons with MS [11,12]; strength and range of motion, as well as decreased pain and weight loss in spinal cord injury wheelchair users [29]; gait and balance in a senior with chronic stroke [30]; attention, working memory, memory, and executive functioning in individuals with mild cognitive impairment [13]; physical activity, functional capacity, quality of life, vitality, social function, and mental health in cancer survivors [8,31], and metabolic control and motivation in individuals with diabetes/obesity [7].

In addition, many of these studies found that participants enjoyed the dance classes and would continue taking them if given the opportunity. Dance is also linked to music and requires the physical closeness of a partner, which is different from most other exercise activities, creating a more fun and social form of exercise [22]. Therefore, ballroom dance may provide an enjoyable form of exercise that improves fitness and encourages a more active lifestyle in populations that struggle to participate in traditional forms of exercise. Beyond a good workout, dance involves emotion, social interaction, sensory stimulation, motor coordination, and music, and thereby has been deemed more enjoyable, and thus, more sustainable over long periods [14]. All these advantageous features of ballroom 
dance may make it a superior form of rehabilitation for individuals living with chronic neurological or medical disorders/diseases.

Ballroom dance also has several other advantages over other forms of dance. Ballroom dance requires partnership - each movement is successful only if both partners cooperate. Ballroom dance has ten relatively different dance styles that span a broad range of movements and music styles, making it possible for the vast majority of participants to find a dance they like. In addition, ballroom dance movements vary in intensity and tempo of the music so they can be adapted to individuals with various levels of physical functions [8].

There are limitations presented in this current review. First, many of the included studies had small sample sizes, were case or pilot studies, or lacked a control group, making it difficult to conduct a meta-analysis examining how effective ballroom dance provides health benefits to people with chronic medical conditions. Second, our systematic review was not prospectively registered with PROSPERO. However, to the best of our knowledge, this is the first systematic review on the topic of adopting ballroom dance as an alternative rehabilitation modality in people with chronic health problems.

Though the results from the included studies are favorable, additional research is needed to systematically understand the effectiveness of ballroom dance interventions with chronic disease/disorder populations. More research is also needed to compare various populations with chronic conditions such as MS, and spinal cord injury to a control group to verify the extent to which ballroom dance could improve gait, balance, and quality of life. In the future, large-scale randomized controlled trials are necessary to examine the efficacy, retention, and safety of ballroom dance as a rehabilitative intervention. Additionally, it is imperative to systematically determine the biomechanical aspects of ballroom dance in order to fully understand the joint loading and potential injury mechanisms prior to recommending ballroom dance to various populations. A recent study examining the kinetics of the triple-step movement of ballroom dance [32] found that the joint moment is different between the steps of the triple-step movement. More studies are warranted to investigate the kinetic and kinematic perspective of ballroom dance. Further biomechanical analyses of different ballroom dances will provide more evidence and guidance for the application of ballroom dance as a rehabilitative modality in various populations. It is also beneficial to know if one type of dance, such as rhythm (Cha Cha, Rumba, Swing, etc.) or smooth (Foxtrot, Waltz, Tango, etc.), is more effective than another in producing health and mobility benefits.

\section{Conclusions}

Ballroom dance has been broadly used in several populations as an intervention to improve physical function, cognition, and quality of life. As the first of its kind, this review provides a clear and comprehensive picture of the many benefits of ballroom dance in rehabilitative settings. This review highlights some of the potential benefits of ballroom dance interventions with populations suffering from chronic neurological or medical conditions. Ballroom dance is also mentally and physically engaging and has been deemed an effective workout, as well as mood enhancing [12]. Therefore, ballroom dance may serve as an ideal alternative exercise solution for individuals who either struggle to adhere to a traditional exercise program or experience restrictions that prevent them from participating in traditional exercise programs. More large-scale and well-designed randomized controlled trials are needed to further investigate the effects of ballroom dance in providing health benefits to individuals with life-changing health problems.

Author Contributions: Conceptualization, M.W. and F.Y.; methodology, M.W. and F.Y.; investigation, M.W.; resources, M.W. and F.Y.; writing-original draft preparation, M.W.; writing-review and editing, M.W. and F.Y.; supervision, F.Y. All authors have read and agreed to the published version of the manuscript.

Funding: This research received no external funding.

Institutional Review Board Statement: Not applicable. 
Informed Consent Statement: Not applicable.

Data Availability Statement: All data used for this review is presented in Tables 2 and 3.

Conflicts of Interest: The authors declare no conflict of interest.

\section{References}

1. Carr, J.; Shepherd, R. Neurological Rehabilitation: Optimizing Motor Performance, 2nd ed.; Churchill Livingstone Elsevier: Amsterdam, The Netherlands, 2010.

2. Batista, P.; Pereira, A. Quality of life in patient with neurodegenerative diseases. J. Neurol. Neurosci. 2016, 77, 1-7. [CrossRef]

3. Farrell, J.; Merkas, J.; Pilutti, L. The effect of exercise training on gait, balance, and physical fitness asymmetries in persons with chronic neurological conditions: A systematic review of randomized controlled trials. J. Front. Physiol. 2020, $12,1316$.

4. Rahal, M.; Alonso, A.; Andrusaitis, F.; Silva Rodrigues, T.; Souza Speciali, D.; D'Andrea Greve, J.; Eugenio Garcez Leme, L. Analysis of static and dynamic balance in healthy elderly practioners of Tai Chi Chuan versus ballroom dancing. Clinics 2015, 70, 157-161. [CrossRef]

5. Merom, D.; Cumming, R.; Mathieu, E.; Anstey, K.; Rissel, C.; Simpson, J.; Morton, R.; Cerin, E.; Sherrington, C.; Lord, S. Can social dancing prevent falls in older adults? a protocol of the Dance, Aging, Cognition, Economics (DAnCE) fall prevention randomized controlled trial. BMC Public Health 2013, 13, 477. [CrossRef] [PubMed]

6. $\quad$ Licher, S.; Darweesh, S.; Wolters, F.; Fani, L.; Heshmatollah, A.; Mutlu, U.; Koudstaal, P.; Heeringa, J.; Leening, M.; Ikram, M.; et al. Lifetime risk of common neurological diseases in the elderly population. J. Neurol. Neurosci. Psychiatry 2019, 90, 148-156. [CrossRef] [PubMed]

7. Mangeri, F.; Montesi, L.; Forlani, G.; Grave, R.; Marchesini, G. A standard ballroom and Latin dance program to improve fitness and adherence to physical activity in individuals with type 2 diabetes and in obesity. Diabetol. Metab. Syndr. 2014, 6, 74. [CrossRef] [PubMed]

8. Pisu, M.; Demark-Wahnefried, W.; Kenzik, K.; Oster, R.; Lin, C.; Manne, S.; Alvarez, R.; Martin, M. A dance intervention for cancer survivors and their partners (RHYTHM). J. Cancer Surviv. 2017, 11, 350-359. [CrossRef]

9. Chien-Hung, L.; Hung-Chou, C.; Tsan-Hon, L.; Wei, L.; Shih-Ching, C. Exercise interventions for individuals with neurological disorders: A systematic review of systematic reviews. Am. J. Phys. Med. Rehabil. 2019, 98, 921-930.

10. Yang, F. Application of vibration training in people with common neurological disorders. In Manual of Vibration Exercise and Vibration Therapy; Rittweger, J., Ed.; Springer: Cham, Switzerland, 2020.

11. Ng, A.; Bunyan, S.; Suh, J.; Huenink, P.; Gregory, T.; Gambon, S.; Miller, D. Ballroom dance for persons with multiple sclerosis: A pilot feasibility study. Disabil. Rehabil. 2019, 42, 1115-1121. [CrossRef]

12. Mandelbaum, R.; Triche, E.; Fasoli, S.; Lo, A. A pilot study: Examining the effects and tolerability of structured dance intervention for individuals with multiple sclerosis. Disabil. Rehabil. 2016, 38, 218-222. [CrossRef]

13. Lazarou, I.; Parastatidis, T.; Tsolaki, A.; Gkioka, M.; Karakostas, A.; Douka, S.; Tsolaki, M. International ballroom dancing against neurodegeneration: A randomized controlled trial in greek community-dwelling elders with mild cognitive impairment. Am. J. Alzheimer's Dis. Other Dement. 2017, 32, 489-499. [CrossRef]

14. Lakes, K.; Marvin, S.; Rowley, J.; Nicolas, M.S.; Arastoo, S.; Viray, L.; Orozco, A.; Jurnak, F. Dancers perceptions of the cognitive, social, emotional, and physical benefits of modern styles of partnered dancing. Complement. Ther. Med. 2016, 26, 117-122. [CrossRef]

15. Kunkel, D.; Robison, J.; Fitton, C.; Hulbert, S.; Roberts, L.; Wiles, R.; Pickering, R.; Roberts, H.; Ashburn, A. It takes two: The influence of dance partners on the perceived enjoyment and benefits during participation in partnered ballroom dance classes for people with Parkinson's. Disabil. Rehabil. 2017, 40, 1933-1942. [CrossRef]

16. Hackney, M.; Earhart, G. Effects of dance on gait and balance in Parkinson disease: A comparison of partnered and non-partnered dance movement. Neurorehabilit. Neural Repair 2010, 24, 384-392. [CrossRef]

17. Gomes da Cruz, C.; Molina, G.; Porto, L.; Junqueira, L. Resting bradycardia, enhanced postexercise heart rate recovery and cardiorespiratory fitness in recreational ballroom dancers. Res. Q. Exerc. Sport 2017, 88, 371-376. [CrossRef]

18. Lankford, D.E.; Bennion, T.; King, J.; Hessing, N.; Lee, L.; Heil, D. The energy expenditure of recreational ballroom dance. Int. J. Exerc. Sci. 2014, 7, 228-235.

19. Blanksby, B.A.; Reidy, P.W. Heart rate and estimated energy expenditure during ballroom dancing. Br. J. Sports Med. 1988, 22, 57-60. [CrossRef] [PubMed]

20. Huang, S.; Hogg, J.; Zandieh, S.; Bostwick, S. A ballroom dance classroom program promotes moderate to vigorous physical activity in elementary school children. Am. J. Health Promot. 2012, 26, 160-165. [CrossRef] [PubMed]

21. Liiv, H.; Jurimae, T.; Maestu, J.; Purge, P.; Hannus, A.; Jurimae, J. Physiological characteristics of elite dancers of different dance styles. Eur. J. Sport Sci. 2014, 14, 429-436. [CrossRef] [PubMed]

22. Maraz, A.; Kiraly, O.; Urban, R.; Griffiths, M.; Demetrovics, Z. Why do you dance? Development of the Dance Motivation Inventory (DMI). PLoS ONE 2015, 10, e0122866. [CrossRef]

23. Merom, D.; Grunseit, A.; Eramudugolla, R.; Jefferis, B.; McNeill, J.; Anstey, K. Cognitive benefits of social dancing and walking in old age: The dancing mind randomized controlled trial. Front. Aging Neurosci. 2016, 8, 26. [CrossRef] [PubMed] 
24. Zajenkowski, M.; Jankowski, K.; Kolata, D. Let's dance-Feel better! Mood changes following dancing in different situations. Eur. J. Sport Sci. 2015, 15, 640-646. [CrossRef] [PubMed]

25. Sohn, J.; Park, S.-H.; Kim, S. Effects of DanceSport on walking balance and standing balance among the elderly. Technol. Health Care 2018, 26, S481-S490. [CrossRef] [PubMed]

26. Kunkel, D.; Fitton, C.; Roberts, L.; Pickering, R.; Roberts, H.; Wiles, R.; Hulbert, S.; Robison, J.; Ashburn, A. A randomized controlled feasibility trial exploring partnered ballroom dancing for people with Parkinson's disease. Clin. Rehabil. 2017, 31, 1340-1350. [CrossRef] [PubMed]

27. Hulbert, S.; Ashburn, A.; Roberts, L.; Verheyden, G. Dance for Parkinson's-The effects on whole body co-ordination during turning around. Complement. Ther. Med. 2017, 32, 91-97. [CrossRef]

28. Blandy, L.; Beevers, W.; Fitzmaurice, K.; Morris, M. Therapeutic Argentine tango dancing for people with mild Parkinson's disease: A feasibility study. Front. Aging Neurosci. 2015, 6, 122.

29. Masters, B.; Kiratli, J.; Hong, M. Physical benefits in dancers with spinal cord injury participating in six week mixed ability Latin dance class. Phys. Med. Rehabil. 2013, 5, S236. [CrossRef]

30. Hackney, M.; Hall, C.; Echt, K.; Wolf, S. Application of adapted Tango as therapeutic intervention for patients with chronic stroke. J. Geriatr. Phys. Ther. 2012, 35, 206-217. [CrossRef]

31. Schmidt, T.; Rudolph, I.; Wozniak, T.; Ruetters, D.; Van Mackelenbergh, M.; Huebner, J. Effect of ballroom dancing on the well-being of cancer patients: Report of a pilot project. Mol. Clin. Oncol. 2018, 9, 342-346. [CrossRef]

32. Wells, M.; Yang, F. A kinetic analysis of the triple step in recreational swing dancers. Sports Biomech. 2021, 1-14. (online ahead of print) [CrossRef] 